\title{
The Effects of Culture in Foreign Language Curriculum
}

\author{
Kemal Oğuz ER*
}

\begin{abstract}
Ignoring or ommitting the cultural aspects of the language being taught has been a frequently debated topic in the world of education. Therefore, the importance and benefits of exposing foreign language students to the foreign cultures within various educational settings is discussed in this study considering related literature.
\end{abstract}

Key Words: Culture, curriculum, foreign language teaching, second language teaching.

\section{SUMMARY}

According to the results of many research, it is found out that the issue of failing to expose the students to the cultures of the languages that they are learning makes foreign language education is more difficult and less interesting for the students. Besides, these research prove that including cultural aspects into the foreign language curriculum acknowledges students about the other cultures and enables them to develop empathy towards foreigners. Furthermore, it is also proven that enhancing the language curriculum with the cultural aspects makes language learning more sense and much easier for the learners, especially for the primary school students and for those who have never taken any foreign language courses before. For a long time, educators in many countries have understood the importance of teaching cultural information to the foreign language students and therefore, they included in these information in their curriculum. The importance and benefits of exposing foreign language students to the foreign cultures in this study considering the relavent literature within the edecational settings is discussed.

\footnotetext{
* Arş. Gör. Ankara University Departmant of Educational Science
} 


\section{Yabancı Dil Öğretim Programlarında Kültürün Etkileri}

\section{Kemal Oğuz ER*}

ÖZ: Yabanc1 dil öğretiminde öğretilen hedef dilin kültürünün öğretim programları içinde sık sı ihmal edilmesi günümüzde çokça tartışılan ve üzerinde durulan bir konudur. Bu yüzden, bu çalışmada, yabancı dil öğretiminde, öğretilen dilin temel kültürel özelliklerinin, yabancı dil öğretim programlarında yer almasının ve öğrencilere aktarılmasının önemi ve yararları alanyazından yararlanılarak açıklanmıştır.

Anahtar Kelimeler: Kültür, öğretim programı, yabancı dil ögretimi, ikinci dil öğretimi.

Dil, ait olduğu toplumun düşünce biçimini yansıtan bir araçtır. Dil, toplumla birlikte geliştiği için yabancı bir dile hakim olabilmenin ilk şartı o toplum gibi düşünebilmektir. Örneğin; yabancı bir dilde erkek ve kadın için kullanılan kelimeler o toplumda erkek ve kadının sosyal statülerini ortaya koyar. Başka bir örnek vermek gerekirse Türkçe'de söylenen "Dereyi görmeden paçaları sıvama” atasözü İngilizce' de "Şişman kadın söylemeden operayı bitti sanma" şeklinde söylenmektedir. Her iki atasözü de aynı amaçla söylenmiş olsa da kültürel farklılıklar sonucu, farklı biçimlere bürünmüştür (Uyan, 2005, 2).

Goode, Sockalingam, Brown ve Jones 'a göre (2000) kültür, insan davranışı ve onu etkileyen düşünceleri, insanın iletişim becerisi, dili, inançları, değerleri, dini törenleri, toplumda üstlendiği çeşitli rolleri, içinden geldiği ırkı ve dini ve sosyal grup davranışlarından oluşur. Öyleyse dil

* Araş. Gör. Ankara Üniversitesi Eğitim Bilimleri Bölümü, Öğretim Elemanı. 
sadece bizim dil derslerinde tanımladığımız kültürün bir parçası değil aynı zamanda kültürün aktarıcısıdır. Kültür öğeleri ile ilişsilendirilmeyen bir dil birkaç dersle öğretilemez ve öğrenilemez. Bunun için kültür aktarımı yabancı dil ögretiminde önemli bir yer tutar (Aktaran: Peterson\& Coltrane, 2003, 1).

Yabancı Dil Öğretim Programı üzerinde araştırma yapan bilim adamlarının görüssleri incelenecek olursa, Doğru (1996), dilin kültür ile ilişkisini dilin düşünce ile ilişkisinden ayırmanın mümkün olmadığını belirtmektedir. Düşünce, dili etkileyip ondan etkilendiği gibi kültürü de etkiler ve ondan etkilenir. Yani, bunların arasındaki ilişki iç içe geçmiş kaynaşmış bir ilişkidir (Doğru, 1996, 22). Doğru (1996), dilin; düşünsel, toplumsal, dini yönelişleriyle, adet ve ananeleriyle bir milletin aynası olduğunu ve bütün bunların dili etkilediğini, bu etkilerin dilin ifade biçimlerini, kurallarını, ses ve anlatımlarını şekillendirdiğini açıklamaktadır. Asutay (2003), seksenli yıllarda iletişimsel yöntem tartışılırken kültürlerarası iletişim kavramı çerçevesinde yeni bir aşama olarak "kültür kuramı"nın geliştirildiğini belirtmektedir. Bu kuramdaki temel düşünce yabancı dil derslerinde bilinçli ya da bilinçsiz olarak iki farklı kültürün karşı karşıya gelmesidir. Böylelikle yabancı dil derslerinin amacı yabancı kültürü tanımak olarak karşımıza çıkmaktadır ve her yabancı dil dersi aslında bir kültürler arası diyalog olarak gösterilmektedir (Asutay, 2003, 27).

Troike (1989), çocuklarda dil öğrenmenin kısmen bir kültürlenme süreci oluşturduğunu belirtmektedir. Troike (1989), ana dilini öğrenen çocukların aynı zamanda kendi kültürlerini öğrendiklerini bunun için ikinci dili öğrenmenin ikinci bir kültürü gerekli kıldığını açıklamaktadır (Çeviren: Ören \& Efe, 1989,56).

Fink (2003) ve Mairitsch'de (2003), yabancı dil öğretiminde sadece o dilin kurallarının öğretilmesinin, dilin öğrenilmesinde yaygın inanışın aksine yeterli olmadığını, öğretilen dilin sosyal, kültürel, politik, ekonomik yapısının da öğretilmesinin gerekli olduğunu ve öğrencilerin öğrendikleri dilin kültürünün farkında olmalarının gerekliliğini vurgulamaktadırlar.

Jiang (2000), dilin, kültürün önemli bir parçası olduğunu ve kültür içinde önemli bir role sahip olduğunu belirtmektedir. Jiang (2000), dil ve kültürün bir buzdağına benzetildiğini; buzdağının görünen kısmının dil, suyun altında kalan kısmının ise kültürün görünmeyen parçaları olduğundan bahsetmektedir. Jiang'ın (2000), bir başka benzetmesi de şöyledir, "Dil beden, kültür ise kandır. Kültür olmazsa dil ölür. Dil olmazsa kültür şekillenemez". Jiang (2000), bazı sosyal bilimcilerin dilin olmadığı bir kültürün var olamayacağını ve dilin kültürü etkilediğini ve şekillendirdiğini ifade ettiklerini açıklamaktadır. Brown (1994), dilin kültürün, kültürün de dilin bir parçası olduğunu ve birbirlerinden ayrılamayacaklarını ifade 
etmektedir (Aktaran: Jiang, 2000, 1). O halde, yabancı dil öğretiminde kültürel öğelerin aktarılmasını göz ardı etmek o yabancı dilin öğrenilmesini zorlaştıracaktır. Nitekim Çakmak da (2001), yabancı dil öğreniminin yabancı bir dünyayı, yabancı bir kültürü anlamak, tanımak olduğunu ifade etmektedir.

Birdal (2005) ve Hegde'de (2004) dil ve kültürün birbirinden ayrılamayacağını belirtmektedir. Hedge' ye göre (2004) dil kültürle olan ilişkisi oranında anlamlı bir hal alır ve dil kültürün nasıl göstergesi durumunda ise kültür de dilin anahtarıdır, aracıdır; dil ve kültür birbirinden farklı düşünülemez.

Turan (1998), Vossler ve Humboldt'un düşüncelerinden yola çıarak dili kültürün bir aynası olarak nitelemektedir (Aktaran: Abacıoğlu, 2002, 5). $\mathrm{Bu}$ görüsşe göre bir ulusun dilinin incelenmesiyle onun kültürünün ve dünya görüşünün aydınlatılabileceği konusunda fikir edinebiliriz. Ulusların kendi toplumsal gereksinmelerine göre sözcük türettikleri ve ulusal dillerin toplumca önemsenen alanlar ve dallara ilişkin olarak geliştiği, zenginleştiği bilinmektedir (Abacıoğlu, 2002, 5).

Tseng (2002), yabancı dil ve ikinci dil öğretiminde, kültürün eğitim programları içinde sik sik ihmal edildiğini ama yeni dil ve öğretim yaklaşımlarındaki değişikliklerle, kültürün dil öğretiminde özellikle üstünde durulması gereken bir etken olduğunu belirtmektedir. Tseng (2002) ve Gillian (1990) dil öğrenmede başarılı olmak için, dil öğrenen kişinin öğrendiği dilin kültürü hakkında da bilgiye sahip olması gerektiğini ifade etmektedir. Örneğin, yabancı dilde herhangi bir okuma parçasını okuyan bir kişinin öğrendiği dilin kültürü hakkında bilgi sahibi olması okuduğu parçayı daha kolay ve hizlı anlamasına yardımcı olacaktır (Tseng, 2002, 2).

Rosberg (1995), çocukların yabancı dil öğrenimlerine yardım edenlerin, kültürün yabancı dilden önce geldiğini hissettirebilmelerinin önemli olduğunu vurgulamıştır. Rosberg'e göre kültürel içerik yabancı dil öğretiminde motivasyonu sağlar, bunun için, dil dersleri anlamlı ve güncel olmak zorundadır (Rosberg, 1995, 1). Aynı yazar, yabancı kültüre ait kitapların okunmasının çocukları yabacı dil öğrenmeye daha yatkın hale getireceğini ancak öğretmenin kitapları seçerken son derece dikkatli olması gerektiğini, başlangıçta kitapların öğrenilen dilin kültürü hakkında kılişeleşmiş görüşlere yer vermesi yerine, o kültürü tanımlayıcı çocuk kitapları olmasının daha faydalı olacağını ifade etmektedir (Rosberg,1995, $6)$.

Yabancı dil derslerinin öğrenciler tarafından kolayca öğrenilmesi, öğretimin zevkli ve ilgi çekici olabilmesi için öğretilen yabancı dilin kültürüne ait öğelerin aktarımı son derece önemlidir. Tomalin ve 
Stempleski’ye (1993), göre kültür öğelerinin aktarılmasının yedi amacı vardir:

1. Öğrencilerin, her insanın davranışında kültürün etkisi olduğunu anlamalarına yardımcı olmak.

2. Öğrencilerin, yaş, cinsiyet, sosyal sınıf gibi değişkenlerin insanların konuşmalarında ve davranışlarında etkisi olduğunu anlamalarına yardımcı olmak.

3. Öğrencilerin, hedef kültürdeki ortak durumlarda gösterilen ortak davranışların farkına varmalarına yardımcı olmak.

4. Öğrencilerin bazı kelime ve cümleciklerin kültürün bir sonucu olarak hep aynı şekilde birbiri ardına geldiğinin farkına varmalarına yardımcı olmak

5. Öğrencilerin, hedef kültürle ilgili genellemeleri objektif gözle değerlendirmelerine yardımcı olmak.

6. Öğrencilerin, hedef kültürle ilgili bilgi toplama becerilerinin gelişmesine yardımcı olmak.

7. Öğrencilerde, hedef kültürle ilgili merak uyandırmak ve onların o kültürdeki insanlara empati duymalarını sağlamak (Tomalin ve Stempleski, 1993,89).

Demircan (1990), dil kültür ilişkisi hakkında aşağıdaki saptamaları yapmıştır:

1. Yabancı dil öğrenen kişi iletişim açısından gerekli olan kültürel verileri öğrenmeli, iletişim becerilerini edinmelidir.

2. İletişimin kültürel öğelerini edinmek kendi kültürünü bırakmak anlamına gelmez. Böyle bir dönüşüm ancak devlet politikası ile kolaylaştırılabilir.

3. Türklerin yabancı dil öğrenme ihtiyacı kültürel değildir, teknik bilgi aktarımını amaçlar (Demircan, 1990, 26).

Yabancı dil öğretiminde kültürel öğelerin aktarılması günümüzde pek çok yabancı dil programlarında da yer almaktadır. Amerika Birleşik Devletleri Nevada Eyaleti Eğitim Bakanlı̆̆ı'nda Haziran 1997'de işveren temsilcileri, eğitimciler ve ailelerin katılımı ile görüşülüp kabul edilen "yabancı dil öğretim standartları"nda dil ve kültür ilişkisi hakkında da kararlar alınmıştır. Bu kararlardan bazıları şunlardır:

$\checkmark$ Bütün öğrenciler farklı dilleri ve $\quad$ o dillere ait kültürleri öğreneceklerdir. 
$\checkmark$ Öğrenciler, başka dilleri ve kültürleri çalışarak kişisel eğitim seviyelerini yükselteceklerdir.

$\checkmark \quad$ Nevada'daki yabancı dil öğretmenleri hedef dilde akıcı bir şekilde konuşmak, öğretilen dilin kültürü hakkında bilgi sahibi olmak, yabancı dil öğretim tekniklerini bilmek ve bu beceriye sahip olmak zorundadırlar.

$\checkmark \quad$ İlköğretim üçüncü sınıf sonunda öğrenciler, öğrendikleri dil ile Amerikan kültürü arasındaki farklılıkları açıklayabileceklerdir (örneğin; müzik, yemek alışkanlıkları, sanat, oyuncaklar vb).

$\checkmark \quad$ İlköğretim beşinci sınıf sonunda öğrenciler kültürel farklılıkların daha çok farkına varıp öğrendiği yabancı dilin Amerikan kültürüne katkısının farkında olabilecektir.

$\checkmark \quad$ İlköğretim üçüncü sınıf sonunda kendini, öğrendiği dilin sözlü ve sözsüz iletişimi ile (bunlara jest, mimik ve vücut dili de dahildir) ifade edebilecektir (Nevada foreign language standarts, 1999, 4-13-10).

Amerika Birleşik Devletleri West Virginia Eğitim Bakanlığı (2002), yabancı dil öğretim programlarında "kültür" alt başlığı altında; dilin ve kültürün ayrılamaz bir bütün olduğunu, öğrencilerin öğrendikleri dilin kültürü hakkında bilgi sahibi olmadan dilde uzmanlaşmanın olamayacağını belirtmektedir.

Uchihara (2001), Roswell Georgia "Mimosa Elementary School" da uygulanan Georgia İlkögretim Okulu Yabancı Dil Program modelinde (ESFL: Georgia Elementary School Foreign Languages Model Program) (bu modelde yabancı dil olarak öğrencilere Japonca öğretilmektedir) en kayda değer gelişmenin öğrencilerin başka dile ve kültüre karşı olumlu tutum geliştirmeleri olduğunu açıklamaktadır. Programda, öğrenciler Japonca yazmaya, Japon ürünlerine, restoranlarına, ve Japon yaşayışına karşı büyük ilgi göstermişler, çevrelerindeki Japon lokantalarına gidip, Japon yemekleri 1smarlayıp, aynı okulda okuyan Japon arkadaşlarının evlerini ziyaret etmişler ve onların ulusal giysilerini giyip, kültürleri hakkında yakından bilgi almışlardır. Japon kültürü hakkında bilgi veren çeşitli materyalleri de sınıfa getirip arkadaşlarıyla paylaşmışlardır. Bu sayede, öğrendiği dilin kültürü hakkında da bilgi sahibi olarak yabancı dil öğrenen öğrenciler dil öğrenmeye karşı hem daha çok motive olmuşlar hem de daha başarılı bir dil öğrenme sürecinden geçmişlerdir.

Cullen ve Sato (2000), öğretmenlerin öğrencilere öğretmek ihtiyac1 duyduğu kültürün, bir çok yapısının tanımlandığı "kültürel doku" teriminin ilk defa Oxfort tarafından 1994 yılında kullanıldığını belirtiyor. Cullen ve Sato (2000), kültürel yapının öğrencilere aktarımı için, öğrencilere öğrendikleri dilin kültürel özellikleri ile ilgili çok çeşitli ve değişik 
perspektiflerden oldukça çeşitli bilgi verilmesi gerektiğini, bunun içinde aşağıdaki araçların faydalanılabileceğini açıklıyorlar:

$\checkmark$ Video

$\checkmark \mathrm{CD}$

$\checkmark$ Okuma parçaları

$\checkmark$ Internet

$\checkmark$ Hikayeler

$\checkmark$ Şarkılar

$\checkmark$ Gazeteler

$\checkmark$ Mülakatlar

$\checkmark$ Konuk konuşmacılar

$\checkmark$ Anektotlar

$\checkmark$ Fotoğraflar

$\checkmark$ Alan çalışmaları vb (Cullen ve Sato, 2000, 1-2).

Jane (1989), ABD'de ilköğretim okullarında uygulanan iki tür programdan bahsetmektedir. Bunlardan birincisi FLES (Foreign language in the elementary school), ikincisi ise FLEX (Foreing language experience programs) isimli programlardır. Lemke (1993), FLES'in tüm ilköğretim ve ortaöğretim yabancı dil programlarının ana adı olduğunu belirtmektedir $(1993,14)$. FLES programlarının temele alındığı yabancı dil derslerinde öncelik gramer bilgileri çok fazla gözardı etmeden öğrencilerdeki anlama, dinleme, konuşma, okuma ve yazma becerilerini sırasıyla geliştirilmektir. $\mathrm{Bu}$ program haftanın beş günü her defasında otuz dakikalık dersler ile düzenlenir ve öğrenilen dilde akıcı konuşma oldukça önemlidir. Çocuklar, sadece öğretilen yabancı dilin kurallarına odaklanırlar ve bu dersi üç dört yıl üst üste alırlar. Gramer kuralları, onlara öğretim içerisinde dolaylı yoldan etkinlikler içinde kazandırılır.

Jane $(1989,1)$ ve Lemke $(1993,14)$ FLEX programın amacının ise, bir dili tüm kurallarıyla öğretmek değil, öncelikli olarak çocuklara sadece bir değil, birkaç yabancı dili kültür öğeleri ile beraber tanıtmak olarak açıklamaktadırlar. FLEX programında çocuklara en az iki yabancı dilin basit kuralları ile beraber kültür öğelerinin tanıtılması amaçlanır ve öğretilen yabancı dilin kültürüne odaklanılır. Çocuklar yabancı dil dersini haftada bir iki gün görürler ve gramer kurallarına ve akıcı konuşmaya fazla önem verilmez. Böylelikle, yabancı dil dersleri monotonluktan ve sikıcılıktan kurtulur ve öğrenciler ilerideki görecekleri yabancı dil derslerine motive olurlar. Lemke Amerika'daki okulların \%49'unun bu programı uyguladığını belirtmektedir. FLEX programları yabanc1 dil derslerine bir heyecan ve coşku katar (Jane, 1989, 2). 
Avrupa Konseyi (Council of Europe) 2000 y1lındaki bildirgesinde, özellikle öğretilen yabancı dilin sosyokültürel bilgisinin verilmesi gerektiğini belirtmiştir. Avrupa Konseyinin belirttiği sosyokültürel bilgiler şunlardır:

1. Günlük yaşam,

- Yiyecek, içecek, yemek zamanları, masa adabı.

- Resmi tatilleri, Çalışma saatleri.

i. Baş zaman faaliyetleri, hobileri, okuma alışkanlıkları, yaptıkları sporlar vb.

2. Yaşam koşulları,

- Yaşam standartları,

- Ev şartları,

- Refah durumları,

3. Kişiler arası ilişkiler,

- Sınıfsal yapı ve sınıflar arası ilişkiler,

- Kadın erkek ilişkileri,

- Aile yapıları ve ilişkileri, jenarasyonlar arası ilişkiler,

- Politik ve dinsel gruplar arası ilişkiler,

4. Değerler, inançlar ve davranışlar,

- Sosyal sinif,

- Çalışma toplulukları,

- Refah,

- Gelir,

- Gelenekler,

- Sanat,

- Müzik vb.

5. Vücut dili,

6. Sosyal gelenekler,

- Dakiklik,

- Hediyeler,

- Elbiseler,

- Yemekler, içecekler,

- Yasaklar vb.

7. Adet olmuş davranışlar,

- Dini durumlar,

- Doğum, evlilik 
- Evlilik, gösteriler, seremoniler, kutsamalar,

- Festivaller,

- Danslar, vb. (CEF, 2000, 102-103)

Brooks'a (1986) göre de, yabancı dil öğretiminde öğrenciye sunulabilecek kültürel öğelerin bazılarını şunlardır:

$\checkmark$ Selamlaşma, vedalaşma, arkadaşlar arası konuşmalar.

$\checkmark$ İnsanları tanıştırma.

$\checkmark$ Karşılıklı konuşmalarda yaşa, cinsiyete, yakınlık derecesine, sosyal statüye, resmiyete göre kullanılacak sözler ve kalıplar.

$\checkmark$ Sorulmaması gereken sorular.

$\checkmark$ Gelenekler, oyunlar, müzik, telefon konuşmaları.

$\checkmark$ Mektup yazma.

$\checkmark$ Birini davet etme, randevu verme, saatler.

$\checkmark$ Yemek yeme ve içme alışkanlıkları

$\checkmark$ Trafik vb (Brooks, 1986, 124-128).

İngiltere Ulusal Programındaki kültürel farkındalık kısmında öğrencilerin değişik ülke ve kültürleri hakkında bilgi sahibi olmaları gerektiği, öğrendikleri dilin kültürü ile kendi kültürlerini karşılaştırmaları ve hedef dili anadili olarak konuşan kişilerle konuşma alıştırmaları yapılması gerektiği vurgulanmaktadır (Qualification and Curriculum authority, 1999).

Eurydice (2001) Avrupa Birliği'nde, yabancı dil öğretimi ekinde, yabancı dil öğretim programları özet tablosunda, Belçika'nın ilköğretim programında öncelikli hedef "yabancı dil ögrenmeye karşı olan merakı uyanık tutmak" olarak ifade edilirken kültürel hedef olarak da "başka bir dilin kullanımı, kendi kültürümüz dışındaki kültürel yapıyı anlamak ve farklı düşünce yollarını ayırt etmeyi olanaklı kılar" olarak belirtilmektedir (2001, 206). Türk Milli Eğitim Sisteminde de "Türkçe'den başka dillerin de konuşulduğunun farkına varabilme" ve "Farklı kültür ve kültür değerlerini hoşgörü ile karşılayabilme" (M.E.B. Tebliğler Dergisi, sayı 248, Ekim 1997:590) gibi genel ve özel amaçlar ile dil kültür ilişkisine programlarda yer verilmiştir.

Cortazzi ve Jin (1999), dilin bir iletişim aracı olduğunu, iletişimde kültürden ayrılamayacağını belirmektedirler ve İngiltere'de yabancı dil öğretimiyle ilgili çoğu dokümanın üç ana amaç üzerinde odaklandığına işaret etmektedirler. Bunlar: 
1. Dili öğrenen kişinin karşılaşabileceği durumlarda kullanabileceği iletimsel yetiyi geliştirmek.

2. Dilin doğasına ve öğrenimine karşı bir farkındalık oluşturmak.

3. Yabancı kültürü iyice incelemek, yabancı kültürdeki insanlara karşı olumlu tutumlar geliştirmek (Cortazzi \&Jin, 1999, 1).

Brooks (1986), yabancı dil öğretiminde, öğretilen dilin kültür öğelerinin aktarılmaması durumunda öğrencilerin konuștuğu yabancı dilin, kendi kültüründe karşılaştığı olayları farklı kavramlar ve sembollerle aktarmaktan başka bir şey olmayacağını belirtmektedir. Brooks'un bu görüşlerini daha iyi anlayabilmek için Ozil’in 1999 yılında yaptığı çalışmaya bakmak yararlı olacaktır.

Ozil (1999), "Devlet Okullarındaki Dil Derslerinde Hedef Kültüre Ait Öğelerin Aktarılması" isimli çalışmasında Milli Eğitim Bakanlığı’nın devlet okullarında okutulmasına karar aldığı "A Modern English Course For Turks 7" adlı kitabı incelemiştir. Ozil, bu kitabın bir çok yerinde Türk öğrencilere öğrendikleri yabancı dili tanıtmak yerine onların zaten içinde yetiştikleri ve çok iyi bildikleri Türk kültürüne ait okuma parçaları ve gramer alıştırmalarının verildiğini belirtmekte ve bu durumu örnekleriyle şöyle açıklamaktadır:

Örneğin 18. sayfada Nasrettin Hoca'nın "parayı veren düdügü çalar" sözüyle bilinen hikayesi İngilizce olarak anlatılmaktadır. Her Türk’ün bildiği bu hikaye sadece değişik sembollerle anlatılmıştır ve hiçbir merak uyandırıcılığı yoktur.

49. sayfada İngilizce' de iki şeyin karşışaştırılması konusu verilirken bazı örneklerde Sultanahmet Camii ve Sülaymaniye Camii, Kayseri ve Erzurum seçilmiştir.

89. sayfadaki diyalogda ise Beşiktaşlı eski futbolcu Metin Tekin'le yapılan bir röportaja yer verilmektedir. Röpörtajın İngilizce olması inandırıcılıktan çok uzak bir görüntü sergilemekte ve öğrencileri motive edici bir işlev taşımamaktadır (Ozil, 1993,10)

Ozil (1999, 7), yukarıda bahsedilen çalışmasında, Milli Eğitimdeki İngilizce derslerinde kültür öğelerinin gerektiği gibi verilememesinin dört nedeni olduğunu belirtmektedir. Bunlar:

1. Seçilen kitaplar: Kültür öğelerinin bu kadar yetersiz olduğu kitapların seçilmesinde ise akla iki değişik amaç gelmektedir. Devlet ya öğrencilerin değişik kültürlerden etkilenip kendi öz kültürlerini kaybedeceklerinden çekinmekte ve bu seçimi bilinçli şekilde yapmaktadır ya da dil öğretiminde kültür faktörünün önemini kavrayamamıştır. Devletin Milli Eğitim kitaplarını seçmede görevli kadrosunun içinde akademik alanda belli birikimleri olan insanların 
bulunduğu düşünüldüğünde ikinci seçeneğin az olma ihtimali hayli düşük görünmektedir.

2. Öğretmenler: Türkiye'deki sistem içinde yetişen öğretmenlerin bir kısmı öğrencilik yıllarında gördüğü öğretim modelinin aynısını kendi öğrencilerine uygulamakta ve dolayısıyla kültür öğesi göz ardı edilmektedir. Ayrıca öğretmenlerimizin çoğu hedef dilin konuşulduğu ülkeye gitme veya hedef dili ana dili olarak konuşan bir kişiyle iletişim olanağı bulamamaktadır. Bunun sonucunda da bunun farkına varması güçleşmekte ve ekstra çaba gerektirmektedir.

3. Zaman: Hazırlanan programı, belirlenen programı belirlenen zaman dilimi içinde bitirmek zorunda olan ve bu arada sinavlar, beklenmedik tatiller veya çeşitli aksamalar sonucu normal programdan geri kaldığı için koşuşturma içine giren sınıflarda kültür öğelerinin aktarımı için gereken zaman bulunamamaktadır. Zamanın bir kısmı, dersin içeriğine kültür aktarımı katmaya harcandığında genellikle şekil ağırlıklı değerlendirme yapan üst yönetimler teşvik edici olmak yerine programdan geri kalındığı için bu duruma tepki göstermektedirler.

4. Bakış açısı: Türkiye'de eskiden beri süregelen öğrenci, öğretmen, veli ve hatta yabancı dil öğrenen veya öğrenmeyi düşünen birçok kişinin hemfikir olduğu yanlış bakış açısı bir dilin kelimelerinin ve gramerinin öğrenmekle edinilebileceğinin sanılmasıdır.

Sonuç olarak, yabancı dil öğretiminde öğretilen dilin kültürel öğelerine yer vermek, dilin gramer kurallarının yanı sıra, temel kültürel özelliklerini de öğrencilere aktarmak hem öğrenilen dili öğrenciler için daha anlamlı hale getirecek hem de yabancı dil öğrenmenin, zor, sıkıcı ve uzun zaman alan bir uğraş yerine daha zevkli ve kısa sürede öğrenilen bir uğraş olarak algılanmasını kolaylaştıracaktır. Ayrıca, öğrencilerin başka kültürleri tanıması, dünyada başka yaşam tarzında insanların da olduğunun farkına varması (özellikle küçük yaşta dil öğreniminde), öğrenenleri dil öğrenmeye karşı motive ederek öğrenme hızlarını arttırırken, başka kültürlere sahip insanlar ile arasında empati kurmasına ve yabancı dil öğrenmeye karşı olumlu tutum geliştirmesine de yardımcı olacaktır.

Özellikle, Türk Milli Eğitim sisteminde yabancı dil programlarını yenileme çalışmalarının sürdüğ̈ şu günlerde, yabancı dil programlarına öğretilen dilin kültürel özelliklerinin alınması, içeriğin ve içerikte yer alacak örneklerin, alıştırmaların bu kültürün temel özelliklerine göre düzenlenmesi, öğretme süreçlerinde de kültürel özelliklerden bahsedilmesi için yeterli sürenin ve kaynakların, araç-gereçlerin ayrılması Türkiye'de yabancı dil öğrenen birey sayısını, yabancı dil öğrenme seviyesini ve hızını arttıracaktır. 


\section{KAYNAKLAR}

Abacıŏlu, T. (2002). Çocuklara oyunlarla yabancı dil öğretimi. Yayımlanmamış Yüksek lisans tezi, Gazi Üniversitesi Eğitim Bilimleri Enstitüsü, Ankara.

Asutay, H. (2003). Yabancı dil öğretiminde kültür bağlamı ve öteki dil. Ankara Üniversitesi (TÖMER) Dil Dergisi, Say. 118. Ss,26-29.

Birdal, A. (2005). Yabancı dil öğretiminde "gereksinim çözümlemesi" uygulamasının gerekliliği. (On-line doküman) WEB sayfasından alındığı tarih:08.08.2005.

WEB: http://www.ingilish.com/gereksinim-cozumlemesi.htm.

Brooks, N. (1986). "Culture in the classroom". In J.M. Valdes (Eds) Culture bound (p. 123-129). Cambridge University Press.

Çakmak, M.(2001), "Yabancı dil öğretimi” Küçükahmet, L. (Editör). Ders kitabı Inceleme Kılavuzu Yabancı Dil 4-8. Ankara: Nobel Yayın Dağıtım.

Cortazzi, M.\& Jin, L. (1999). "Kültürel aynalar" Yabancı dil sınıfındaki materyal ve yöntemler. (İngilish. Com adresinde yayınlanan makale) Makalenin WEB sayfasından alındığı tarih: 14.07. 2005.

WEB: http://www.ingilish.com/kültür-ögrenimi.htm

Cullen, B.\& Sato, K. (2000). Practical techniques for teaching culture in the EFL classroom. (The Internet TESL Journal, Vol. VI, No. 12 December). WEB Sayfasından alındığı tarih: 15.07.2003.

WEB: http://iteslj.org/ Techniques/Cullen-Culture.html

Demircan, Ö. (1990). Yabancı dil öğretim yöntemleri. İstanbul: Ekin EğitimYayıncılık ve Dağıtım.

Doğru, E. (1996). Dil, düşünce ve kültür arasındaki ilişki. Ankara Üniversitesi (TÖMER) Dil Dergisi, 45 S. 15-25.

EURYDICE European Commission (2001). Foreign language teaching in school in Europe (Eurydice Studies). Belgium: Directorate General for Education and Culture.

Fink, C. (2003). "Culturel awareness". In Hanak, M \& Newby, H.,D. (Eds) Second language acquisition: The interface between theory and practise (p.65-69). Makalenin WEB sayfasından alındığı tarih: 06.08.2005.

WEB:

http://www.ecml.at/documents/relresearch/projectseminarDN.pdf 
Hedge, M.,N. (2004). A coursebook on language disorders in children. Singular Publishing Group İnc. San Diego-London.

Jane, R. (1989). Elementary school foreign programs. (On-line Doküman). WEB Sayfasından alındığ tarih: 05.08.2005.

WEB: http://ericdigests.org/pre-9212/programs.htm

Jiang, W. (2000). The realation between culture and language. ELT Journal Volume 54/4 October. Oxford University Pres. (On-line doküman). Makalenin WEB sayfasından alındığ 1 tarih: 07.09. 2005.

WEB. http://eltj.oxfordjournals.org/cgi/reprint/54/4/328.pdf.

Lemke, L.,A., (1993). Elementary foreign language program in the grand blanc community schools, 1993-1994 (K-3): A Paractical Handbook. (On-line doküman). WEB Sayfasından alındığı tarih: 27.04.2004.

WEB: http://www.edrs.com/Doclibrary/0496/ed368203.pdf.

Mairitsch, B.(2003). Culturel Awareness. In Hanak, M \& Newby, H.,D. (Eds) Second language acquisition: The interface between theory and practise (p.48-52). Makalenin WEB sayfasından alındığ 1 tarih: 05.08.2005.

WEB:

http://www.ecml.at/documents/relresearch/projectseminarDN.pdf

M.E.B. (1997). Tebliğler Dergisi. Say1 2481, Ekim:590.

Nevada State Dept. Of Education (1999). Nevada foreing language standarts: Content standarts for grades kindergarden, 3,5,8 1st year high school study 2nd year high scholl study, and 4th year high school study (and) performance standarts. Nevada State Dept of Education, Carson City.

(On-line doküman). WEB Sayfasından alındığı tarih: 15.02.2003.

WEB: http://www.edrs.com/Doclibrary/0496/ed467490.pdf.

Peterson, E. \& Coltrane,B. (2003). Culture in second language teaching. (On-line doküman). WEB Sayfasından alındığı tarih: 03.08.2005.

WEB: http://www. cal.org/resources/digest/0309peterson.html.

QCA (Qualifications and Curriculum Authority). (1999). The rewiew of the national curriculum in England. The consultation materials. (On-line doküman). WEB sayfasından alındığı tarih: 05.09.2005).

WEB: http:www.qca.org.uk 
Ozil, Ş. (1999). Devlet okullarındaki yabancı dil derslerinde hedef kültüre ait öğelerin aktarımı. (İngilish. Com adresinde yayınlanan makale) Makalenin WEB sayfasından alındığı tarih: 15.07. 2005

WEB: http://www.ingilish.com/kultur-aktarimi.htm

Rosberg, M. (1995). Teaching English as a second language: How young children learn. (On-line doküman). WEB Sayfasından alındığı tarih: 27.04.2004.

WEB: http://www.edrs.com/Doclibrary/0496/ed389227.pdf

Uchihara, A. (2001). Japanese at mimosa elementary school. Learning Language Volume 7, number 1.

Tomalin, B. \& Stemplesli, S. (1993). Cultural awareness. Oxford University Pres.

Troike, M.S. (1989). (Çeviren: Ören\&Efe.1989). Ingilizce Öğretiminde Psikolojik Temeller. Erzurum:Atatürk Üniversitesi Fen Edebiyat Fakültesi Yayın No:85. Sosyoloji Bölümü Yayın No. 6.

Tseng, Y.,H.(2002). A lesson in culture. ELT Journal volume 56/1, January. Oxford University Pres. (On-line doküman). Makalenin WEB sayfasından alındığ tarih: 06.09. 2005.

WEB: http://eltj.oxfordjournals.org/cgi/reprint/56/1/11.pdf

West Wirginia Department of Education (2002). Middle childhood and adolescent foreign language education. (Online doküman). WEB sayfasından alındığı tarih: 04.07.2003.

WEB: wvde.state.wv.us/policies/p2520_flhtml 